\title{
Formação de adultos pouco escolarizados: paradoxos da perspectiva da aprendizagem ao longo da vida
}

\author{
Carmen Cavaco*
}

\section{Resumo}

Neste artigo, procura-se analisar criticamente a perspectiva política da Aprendizagem ao Longo da Vida, tendo como referência as políticas e práticas orientadas para os adultos pouco escolarizados, em Portugal. Considera-se que, contrariamente ao discurso político da Agenda Europeia e das orientaçóes políticas nacionais, a perspectiva da Aprendizagem ao Longo da Vida não visa uma educação para todos, nem todo o tipo de educação. A análise que se apresenta resultou de uma investigação de natureza qualitativa, que se baseou na recolha documental e estatística. Estes dados foram complementados com informação recolhida através de entrevistas, num território do sul de Portugal, composto por cinco municípios. Os dados empíricos recolhidos evidenciam que as orientaçôes políticas referentes à perspectiva da Aprendizagem ao Longo da Vida dão lugar a práticas muito circunscritas de formação, que não atendem à riqueza e diversidade dos processos educativos e que, por esse motivo, não envolvem a globalidade dos cidadãos. A maior parte da formação realizada no território em estudo é orientada para adultos activos e baseia-se na forma escolar, o que dificulta a participação dos adultos pouco escolarizados.

Palavras-chave: Educação de Adultos. Política de Educação de Adultos. Adultos não escolarizados.

*Doutora em Ciências da Educação pela Universidade de Lisboa. Professora Auxiliar do Instituto de Educaçăo da Universidade de Lisboa. 


\section{Introdução}

As políticas educativas emergentes na última década, em Portugal, são tributárias da perspectiva da Aprendizagem ao Longo da Vida, que surgiu na década de 90, sob a égide da Comissão Europeia, e foi difundida no Livro Branco sobre a Educação e a Formação - Ensinar e Aprender - rumo à sociedade cognitiva, em 1995, e foi reforçada em 2000, com o memorando sobre a Aprendizagem ao Longo da Vida.

A análise destes dois documentos revela a finalidade da perspectiva da Aprendizagem ao Longo da Vida, que consiste na necessidade de se investir fortemente na educação e formação como estratégia para o desenvolvimento económico da Europa. Veicula-se a ideia da importância da economia Europeia se tornar competitiva face à dos Estados Unidos da América e do Japão, e que para se conseguir tal desígnio seria essencial o investimento na educaçáo e formação das pessoas, as quais são entendidas enquanto recursos humanos.

A perspectiva da Aprendizagem ao Longo da Vida é fortemente influenciada pela Teoria do Capital Humano, partindo do pressuposto, que o investimento na educação e formação se traduzem de uma forma directa e linear em desenvolvimento económico. Esta ideia é repetida inúmeras vezes ao longo dos dois documentos em análise, num dos casos afirma-se que em meados dos anos 1990, "[...] o consenso era geral em torno da ideia de que náo apenas a educação e a formação ao longo da vida contribuem para manter a competitividade económica e a empregabilidade, como constituem igualmente o melhor meio de combater a exclusão social" (CCE, 2000, p. 7). A educação e formação, nesses dois documentos, são consideradas a "[...] chave do reforço da competitividade da Europa, da melhoria da empregabilidade e da adaptabilidade da força de trabalho" (CCE, 2000, p. 5).

A perspectiva da Aprendizagem ao Longo da Vida, inicialmente, formulada pela União Europeia em meados dos anos 1990, mais tarde adoptada e difundida pela UNESCO, é distinta do Movimento da Educação Permanente, que emergiu nos anos 1970. À semelhança de outros autores (CANÁRIO, 1999; CARRÉ; CASPAR, 1999; LAOT; ORLY, 2004; LE GOFF, 1996) consideramos que entre o Movimento da Educação Permanente e a perspectiva da Aprendizagem ao Longo da Vida se registou a erosão das finalidades associadas à educação. A educaçáo deixou de ser orientada para o desenvolvimento humano e para a mudança social, para ser um instrumento ao serviço do desenvolvimento 
económico e da resolução dos problemas sociais, como o desemprego e a exclusão social, num lógica de adaptação. Como refere Rui Canário (2001a, p. 195), na perspectiva da Aprendizagem ao Longo da Vida regista-se "a subordinação funcional das políticas de educação e de formação à racionalidade económica dominante". Nas últimas duas décadas, esta perspectiva política foi adoptada pelas várias organizaçôes internacionais como a UNESCO (CAVACO, 2009) e a OCDE, e difundiu-se a nível mundial, contribuindo para a formulação da Agenda global de educação (DALE, 2004). As políticas educativas, que até muito recentemente eram, sobretudo, determinadas a nível nacional, estão a ser cada vez mais "[...] elaboradas através das agendas estabelecidas pela economia política global” (DALE, 2004, p. 441).

Neste artigo, procura-se analisar criticamente a perspectiva política da Aprendizagem ao Longo da Vida, tendo como referência o contexto Português e as políticas públicas orientadas para os adultos pouco escolarizados. É nosso objectivo evidenciar que as "[...] práticas discursivas não são inocentes" (PINEAU, 1977 , p. 2) e que revelam, por vezes, enormes incoerências na sua materialização. À semelhança do que é defendido por vários autores (LIMA, 1994, 2005; CANÁRIO, 1999, 2001a; NÓVOA; RODRIGUES, 2005), consideramos que a perspectiva da Aprendizagem ao Longo da Vida é uma das retóricas mais contundentes das últimas décadas. $\mathrm{O}$ direito à educação, reivindicado pelos cidadãos, "[...] tende a transformar-se num dever e numa imposição de sociedades que olham para as pessoas apenas como 'activos' ou como recursos humanos" (NÓVOA; RODRIGUES, 2005, p. 12). Nesse sentido, parece-nos essencial analisar criticamente o discurso que está subjacente à perspectiva da Aprendizagem ao Longo da Vida, porque a "desconstrução" crítica permite compreender as contradiçóes e alguns efeitos perversos desta retórica.

Partimos do princípio que a perspectiva da Aprendizagem ao Longo da Vida "[...] terá em muitos casos banalizado e naturalizado uma problemática, conferindo-lhe mais um estatuto de prioridade retórica do que propriamente de prioridade política" (LIMA, 1994, p. 21). Neste artigo, considera-se que, contrariamente ao discurso político contemplado nos documentos da Comissão Europeia e nas orientaçóes políticas nacionais, a perspectiva da Aprendizagem ao Longo da Vida não visa uma educaçáo para todos, nem todo o tipo de educação. Na nossa óptica esta é uma das contradiçôes do discurso que enquadra a perspectiva e influencia, de um modo particularmente notório, a participação dos adultos pouco escolarizados em dinâmicas de educação e formação. Essa 
perspectiva educativa enquadra-se num modelo social que tem contribuído para que a vida se torne numa "capitalização económica do self" (ROSE, 1999), sendo as pessoas entendidas como meros recursos e responsabilizadas por tudo o que lhes acontece ao longo da vida, mesmo quando os seus problemas resultam do sistema social, político e económico.

Perante esta situação, interessa-nos compreender de que modo o discurso sobre a Aprendizagem ao Longo da Vida se reflecte nas políticas públicas de educação de adultos a nível nacional e nas lógicas de acção dos actores locais, assim como na adesão à formação, por parte dos adultos pouco escolarizados.

A problemática da aprendizagem ao longo da vida, após o surgimento da perspectiva da Aprendizagem ao Longo da Vida, foi banalizada e associada de imediato à perspectiva política, porém, uma e outra referem a dimensôes distintas. A problemática da aprendizagem ao longo da vida refere-se ao processo natural e contínuo de aprendizagem, que sempre existiu desde os primórdios da Humanidade, porque a aprendizagem é uma capacidade fundamental para a resolução de problemas e para a sobrevivência do ser humano. Quanto à perspectiva da Aprendizagem ao Longo da Vida como se referiu anteriormente é uma orientação política da União Europeia, que data de meados dos anos 90 e que, paulatinamente, foi ganhando projecção a nível internacional. $\mathrm{O}$ facto de haver a sobreposição entre a designação do processo e a orientação política, facilmente, se incorre no risco de associar e congregar ambas, como se tratasse do mesmo. Essa confusão tem contribuído também para a banalização e naturalização da problemática da aprendizagem ao longo da vida, o que dificulta o distanciamento necessário para a "desconstrução" deste discurso e dos seus fundamentos e para uma análise critica das práticas de formação que lhe estão associadas. Dessa forma, procuramos fundamentar os motivos pelos quais consideramos que as orientaçóes políticas referentes à perspectiva da Aprendizagem ao Longo da Vida dão lugar a práticas muito circunscritas de formaçáo, que não atendem à riqueza e diversidade dos processos educativos e que não envolvem a globalidade dos cidadãos.

\section{Responsabilização individual na construção de biografias significativas}

A perspectiva da Aprendizagem ao Longo da Vida assenta no pressuposto da necessidade de se garantir uma aprendizagem desde o início até ao fim da 
vida, para assegurar a empregabilidade, a inclusão social, a competitividade e o desenvolvimento económico (CCE, 2000). A aprendizagem é uma capacidade inata do ser humano, fundamental para a sua sobrevivência (ILLICH, 1971). Porém, nesta perspectiva tem-se uma percepçáo limitada e instrumentalizada da aprendizagem, ao entendê-la unicamente enquanto contributo para a vida profissional e, consequentemente, para o desenvolvimento económico. Sendo assim, a aprendizagem é um processo que resulta de dinâmicas individuais e colectivas e advém da apropriação das experiências de vida (CAVACO, 2002; DOMINICÉ, 1989; JOSSO, 2002).

O Memorando sobre a Aprendizagem ao Longo da Vida é estruturado em torno de seis mensagens que definem a acção política. A quarta mensagem aborda a importância de se "[...] aproximar a aprendizagem dos indivíduos" (CCE, 2000, p. 21), como se a aprendizagem fosse dissociável das pessoas. A análise do discurso desses documentos revela que a educação e formação são entendidas enquanto mercadorias, que funcionam numa lógica de oferta de serviços, por isso mesmo exterior às pessoas. Ignora-se a educação e formação enquanto processos construídos, individual e colectivamente, pelas pessoas na sua vida quotidiana.

O discurso que enquadra a perspectiva da Aprendizagem ao Longo da Vida centra-se na responsabilidade individual, considerando que a aprendizagem é um direito e um dever dos cidadãos, que estes têm de assumir para evitar situaçóes de exclusão social e profissional. Quando se declara que "a aprendizagem ao longo da vida é uma questão que afecta o futuro de todos, de forma perfeitamente individualizada" (CCE, 2000, p. 3), verificamos que há um objectivo peremptório de responsabilização individual pelas questões da aprendizagem.

Os argumentos que enquadram a perspectiva da Aprendizagem ao Longo da Vida se suportam num discurso orientado para a responsabilização individual, entendendo que "[...] cada um deve ter consigo próprio a relação de um empreendedor com o seu produto, procurar 'vender-se', negociar o 'capital' em que se tornou" (DUBAR, 1996, p. 23). Para Claude Dubar (1996, p. 23), o discurso assente na responsabilização individual, que começou por se manifestar como "uma ideologia minoritária [na Europa] e tida como incongruente, tornou-se moeda de troca, um tipo de pensamento único", o que reduz a nossa capacidade de distanciamento crítico perante essa nova perspectiva, que tem um conjunto de consequências na forma como se entendem os processos 
de educação e formação. $\mathrm{O}$ discurso direccionado para a autonomia e para o controlo da própria vida responsabiliza as pessoas por tudo aquilo que lhes possa acontecer, ideia que é reforçada no referido Memorando quando se afirma que as pessoas "[...] têm de querer e ser capazes de assumir o controlo das suas próprias vidas" (CCE, 2000, p. 8).

A educação é um direito mas, essencialmente, um dever que cada um terá de assumir, enquanto responsável pelo seu sucesso e insucesso, numa lógica de "gestão de si". O discurso ao centrar-se na responsabilização individual permite legitimar facilmente os problemas sociais gerados, em grande medida, pelo modelo de desenvolvimento económico, como se fossem problemas individuais, provocados por cada um de nós, em resultado da nossa incapacidade e incompetência para gerir a vida, em geral, e o saber, em particular. É também nesse sentido que Bernard Liétard (1997, p. 73) coloca a seguinte questão: "a focalização sobre a responsabilidade individual na gestão do 'capital de competências' não será, por vezes, uma estratégia de camuflagem ou um engodo para dissimular o papel dos determinismos sociais, económicos e organizacionais no sucesso ou no insucesso?".

A perspectiva da Aprendizagem ao Longo da Vida, ao fundamentarse na responsabilização individual, "[...] permite 'acusar a vítima' tida por única responsável pela sua própria desgraça, recomendar-lhe o self-help" (BOURDIEU, 1998, p. 9-10). A retórica inerente a essa perspectiva aludida pela Comissão Europeia rapidamente teve eco em organismos com projecção internacional, como foi o caso da UNESCO, os quais passaram a incidir o discurso na responsabilização individual, ao defenderem que "[...] os indivíduos devem assumir e responsabilizar-se pela sua vida" (UNESCO, 1997b, p. 137). Esse discurso, que serve de base às políticas de educação e formaçáo, ao incidir na responsabilização individual contribui para o agravamento das desigualdades sociais, colocando os adultos pouco escolarizados numa situação desfavorável. Nos documentos da UNESCO (1997a, p. 20) difunde-se como sendo fundamental que os "indivíduos e as comunidades possam agarrar a sua sorte e a da sociedade para fazer face aos desafios do futuro".

Corroboramos a ideia de Pierre Caspar (1996, p. 9), pois "o que para uns, quer dizer fazer face, significa para outros ficar abandonado a si próprio correndo o risco de se assumir como o único responsável da sua própria desgraça". Esse discurso abre espaço para se considerarem apenas válidas e pertinentes as dinâmicas que consistem numa oferta de educação e formação, 
oferta essa que é, essencialmente, procurada pelos adultos mais escolarizados (SANZ FERNANDEZ, 2005). Cada pessoa é responsabilizada pela construção de percursos de formação adequados e pertinentes, como forma de assegurar a sua qualificaçáo e a inserçáo profissional, tendência que se enquadra na "individualização dos percursos de vida e na responsabilidade privatizada de construir biografias significativas" (FINGER; ASÚN, 2003, p. 118). A ênfase na responsabilização individual, ideia estruturante da perspectiva da Aprendizagem ao Longo da Vida, influencia, decisivamente, a percepçáo da alfabetizaçáo e a educaçáo de base de adultos, como se poderá perceber no ponto seguinte. Por esse motivo, consideramos que os fundamentos que estruturam o discurso sobre a perspectiva da Aprendizagem ao Longo da Vida induzem políticas públicas de educação e formaçáo que deixam de fora uma parte dos adultos - os não activos e os que têm escolaridade mais reduzida.

A UNESCO (1997a) quando refere nos seus documentos "agarrar a sua sorte e a da sociedade" parece fundamentar-se numa ideia determinista, em que os acontecimentos individuais e sociais surgem como inevitáveis. Nesse caso, não são passíveis de alteração nem é possível equacionarem outras possibilidades.

A vida social e individual surge como algo predeterminado e a educaçáo tem a finalidade de preparar as pessoas para a adaptação a essas situaçóes, nomeadamente, para aquelas que são menos positivas, como o desemprego, a precariedade e sofrimento no trabalho, e as desigualdades sociais. Ocultam-se as possibilidades de mudança que as dinâmicas de educação e formação encerram. Como defendia Paulo Freire (1972), "mudar é difícil mas é possível" e a educação têm um papel muito importante na mudança. As dinâmicas de educação e formação que permitem a "leitura do mundo" possibilitam a intervenção e a mudança individual e colectiva. A perspectiva da Aprendizagem ao Longo da Vida visa promover a adaptação e contribui para a resignação face à situação social, económica e política, trata-se de "[...] uma concepção educativa que retira à educação, como aventura humana de conhecer e transformar o mundo, o material essencial de que esta se alimenta: o sonho, a utopia e o projecto" (CANÁRIO, 2001a, p. 205).

As políticas e práticas de educação de adultos enquadradas nessa perspectiva são "agora um produto da sociedade muito mais do que uma força motriz da sua transformação" (FINGER; ASÚN, 2003, p. 118). As principais finalidades da educação de adultos passam a ser a promoção das competências que facilitam a inserção profissional e a ocupaçáo de adultos desempregados. 
Desse modo, a educação de adultos "[...] já não prossegue o projecto da emancipação e da mudança social, tendo-se as suas práticas originariamente emancipatórias tornado distorcidas, instrumentalizadas ou contraprodutivas" (FINGER; ASÚN, 2003, p. 111) e "mais portadoras de desigualdades" (DUBAR, 1996, p. 20), o que se reflecte negativamente na educação e formação dos adultos pouco ou nada escolarizados.

\section{Omissão da abrangência da educação de adultos e a sua "mercadorização"}

Atendendo ao que foi anteriormente destacado, não é anódina a inexistência de referências, nos documentos oficiais da Comissão Europeia, ao termo "Educação de Adultos", pois esse campo está fortemente associado a práticas de Educação Popular, com finalidades emancipatórias, orientadas para a autogestáo e para a autonomia. Como se pode depreender, há uma contradição evidente entre o que é preconizado pela perspectiva da Aprendizagem ao Longo da Vida e os princípios fundadores da Educação de Adultos, enquanto prática social e campo científico. Por um lado, assegurase uma ruptura com o passado e com os domínios sociais que possam ser mais críticos e defensores de processos formativos amplos, numa lógica de construção de alternativas face à hegemonia do modelo de desenvolvimento económico. Por outro lado, na perspectiva da Aprendizagem ao Longo da Vida a educaçáo é instrumentalizada ao serviço das políticas de emprego e sociais, o que permite também justificar as razóes pelas quais não se tem em conta a diversidade de práticas de Educação de Adultos. Os documentos orientadores em análise mencionam apenas as práticas de educação e formação que se baseiam numa lógica de oferta e omitem a importância das dinâmicas construídas à medida das situaçôes, com a intervenção dos vários actores. As dinâmicas de alfabetização e educação de base, de animação, de intervençáo comunitária, de desenvolvimento local integrado e sustentado, e de formação que não se organizam segundo a lógica da oferta e procura não são mencionadas, o que deixa antever a sua desvalorização.

Essa situação leva-nos a considerar que a perspectiva da Aprendizagem ao Longo da Vida é caracterizada por um paradoxo - por um lado, não contempla todo o tipo de educaçáo, por outro lado, não prevê a educação e formação para todos. Nesses documentos orientadores, embora mencione 
a importância da educação não formal e informal, percebe-se a primazia atribuída à educação formal, como consta na afirmação: "para que uma pessoa possa exercer melhor a sua responsabilidade na construção da sua qualificação, é necessário que possa primeiro integrar-se mais facilmente nos sistemas de formação institucionais" (CCE, 1995, p. 19). Nesse sentido, defende-se que os indivíduos devem estar motivados para a aprendizagem e informados sobre a oferta formativa e ser capazes de despoletar a procura daquilo que mais lhes interessar (CCE, 1995). Destaca-se a importância de "[...] aumentar a oferta e a procura de oportunidades de aprendizagem" (CCE, 2000, p. 9). Os referidos documentos, do ponto de vista dos princípios, evidenciam a importância dos processos educativos não formais e informais, contudo quando o discurso é orientado para medidas estratégicas, as preocupaçóes recaem apenas nas dinâmicas educativas institucionais, que se organizam segundo uma lógica de oferta e procura. Do ponto de vista teórico, sabemos que a aprendizagem é um processo que ocorre em todos os tempos e espaços de vida, confunde-se com os processos de socialização, está intimamente associadas às experiências de vida, resulta da influência de contextos e de pessoas significativas, mas depende sempre da apropriação individual, e é um processo difícil de controlar e antecipar (DOMINICÉ, 1989). A perspectiva da Aprendizagem ao Longo da Vida enfatiza, sobretudo, a educação e formação de natureza formal, nomeadamente, os "processos individuais de aprendizagem aparentemente neutros e despolitizados, que são processos de ajustamento e adaptação funcional aos imperativos do capitalismo global" (LIMA, 2005, p. 43).

Nos documentos oficiais da Comissão Europeia, nomeadamente, no Livro Branco sobre a Educação e Formação (CCE, 1995) e no Memorando para a Aprendizagem ao Longo da Vida (CCE, 2000), são mencionados apenas os jovens e os adultos activos, ou seja, aqueles empregados e desempregados. O que nos suscita um conjunto de questôes: Por que motivo sáo ignorados os designados "não activos"? Numa Europa visivelmente marcada pelo envelhecimento populacional por que razão não são previstas políticas públicas de educação e formação orientadas para os idosos? Tratando-se de uma política que incorpora na sua designaçáo a ideia de que se aprende ao longo da vida, em todos os espaços e tempos, por que é que não se contempla a educação e formação de todos os cidadáos, independentemente do seu papel social? Esta opção revela-nos a essência do discurso em que assenta a perspectiva da Aprendizagem ao Longo da Vida, ou seja, a educação e formação são 
manifestamente orientadas para a preparação para o trabalho, numa tentativa de resolver ou minimizar o desemprego entre os jovens e os adultos activos.

No Livro Branco estas opçóes são confirmadas quando se destaca que se "[...] parte deliberadamente da situação do cidadão europeu, jovem ou adulto confrontado com o problema da sua adaptação a novas condiçóes de acesso ao emprego e à evolução do trabalho" (CCE, 1995, p. 5). As referidas orientações se traduzem directamente na acção da Comissão Europeia e dos vários Estados-Membros, como é o caso de Portugal. As metas apontadas pela União Europeia e por Portugal para a participação de adultos em formação, até 2020, contemplam somente pessoas entre os 25 e os 64 anos (CNE, 2011, p. 209). Por que motivo não são considerados os adultos, independentemente, da sua idade e situação face à actividade profissional? A análise do discurso político presente nos documentos orientadores da perspectiva da Aprendizagem ao Longo da Vida e das orientaçóes daí decorrentes, permite-nos afirmar que as políticas da União Europeia que enquadram as políticas públicas dos vários Estados-Membros não se destinam a todos os adultos, o que tem um conjunto de implicaçôes que merecem ser equacionadas.

Nas orientaçóes políticas da União Europeia centradas na perspectiva Aprendizagem ao Longo da Vida (CCE, 1995, 2000) o discurso suprime as medidas de alfabetização e educação de base de adultos, em proveito da formação profissional. Por outro lado, o enfoque na responsabilização individual na procura e selecção das ofertas de educação e formação mais adequadas, colocam os adultos analfabetos e pouco escolarizados numa situação de desvantagem. Esses adultos raramente têm os meios para aceder e gerir a informação e, por várias razōes, não interiorizaram a necessidade da "gestão de si". Exigir às pessoas uma postura de responsabilização na construçáo e evolução do seu saber, centrada unicamente na educação formal é, no caso dos adultos não escolarizados e pouco escolarizados, uma exigência que os coloca em desvantagem e gera desigualdade de oportunidades. As orientaçóes políticas baseadas na perspectiva da Aprendizagem ao Longo da Vida reforçam as desigualdades e penalizam os que não tiveram acesso a uma boa formação de base. Como tal, a ideia de promover uma nova oportunidade àqueles cuja escolaridade "[...] foi marcada pelo insucesso e a ideia de promover formação às pessoas em maior dificuldade náo encontrou o seu caminho. As questôes não estão resolvidas e a situação destas pessoas viu-se agravada" (DUBAR, 1996, p. 19). 
Essa perspectiva ao colocar o enfoque na responsabilização individual, em termos de procura de formaçáo, contribui para que o próprio sistema de educação e formação origine desigualdades no acesso e no sucesso. Como reforça Claude Dubar (1996, p. 20), "percebe-se que o emprego e o sistema educativo geram cada vez mais desigualdades e que a formação acompanha e reforça essa tendência". Situação particularmente evidente em Portugal, na última década, com o desinvestimento público em políticas de alfabetização de adultos, ainda que a taxa de analfabetismo literal se situe nos $5 \%$ (INSTITUTO NACIONAL DE ESTATÍSTICA, 2011). O desinvestimento nas políticas públicas de alfabetização e educação de base de adultos, em Portugal, é visível quando se analisa a evoluçáo do número de adultos inscritos no $1^{\circ}$ ciclo, do ensino recorrente, entre 2000 e 2011. No período em análise, registou-se uma reduçáo superior a 90 por cento no número de adultos inscritos. No ano 2000 estavam inscritos 16.544 adultos, em 2011 apenas 371 adultos, a nível nacional. Se considerarmos os cursos Educação e Formação de Adultos (EFA) orientados para o $1^{\circ}$ ciclo, percebe-se que em 2011 estavam inscritos apenas 2.487 adultos. Entre 2000 e 2011, registaram-se opçóes políticas no sentido de extinguir os cursos de Educação e Formação de Adultos orientados para a certificação escolar de quatro anos de escolaridade, como ressalta um promotor local, "houve orientaçóes para que não fizéssemos B1". Esses valores dão-nos conta de um retrocesso nas políticas públicas de alfabetização e educação de base de adultos, no período entre 2000 e 2011, o que é paradoxal, porque coincide com o período áureo da perspectiva da Aprendizagem ao Longo da Vida, registandose a orientação de avultados recursos financeiros, do Fundo Social Europeu e do Estado Português, para as políticas públicas de educação e formação.

Nos documentos orientadores da perspectiva, verifica-se também uma tendência na alteração do papel atribuído ao Estado e uma grande aposta em parcerias e na responsabilizaçáo da sociedade civil, o que resulta de "[...] uma pressão do mercado para a privatizaçáo" (FINGER; ASÚN, 2003, p. 111). Esta tendência está presente na Agenda Global e influencia os Estados a nível internacional (DALE, 2004; GIDDENS, 2000; GONTCHAROFF, 1999). Roger Dale (2004, p. 440), diz que a política educacional "[...] permanece em grande parte sob o controlo do Estado, contudo novas e cada vez mais visíveis formas de desresponsabilizaçáo estáo a prefigurar-se", em resultado do surgimento do Estado neoliberal. Desse modo, a educaçáo de adultos deixa de ser responsabilidade da administração pública e passa a ser responsabilidade 
de entidades privadas. Esse processo tido como inevitável, nos referidos documentos, resulta, em grande medida, da "[...] subordinação da educação à lógica mercantil, induzindo a que a própria educação se organize adoptando a racionalidade económica do mercado" (CANÁRIO, 1999, p. 90).

A alteração do papel do Estado, através da delegação de competências, da descentralização e da aposta em parcerias, repercute-se também nas práticas de alfabetização e de educação de base de adultos. Nesse domínio, prevê-se que o Estado assegure, essencialmente, a definição de políticas, o financiamento das práticas, os referenciais de competências, a acreditação das entidades formadoras, a formação dos formadores e a disseminação de boas práticas. Em Portugal, na última década, como se verifica através dos dados estatísticos identificados anteriormente, as reformulaçóes do papel do Estado e ao progressivo reforço da lógica de mercado nas práticas de educação de adultos, contribuíram para a demissão do Estado nos domínios da alfabetização e da educação de base de adultos. Durante esse período temporal, o Estado Português não assegurou o direito de acesso à educação aos adultos analfabetos e aos que não completaram os quatro anos de escolaridade, o que é uma contradição atendendo ao discurso político europeu e nacional.

\section{Perspectiva da Aprendizagem ao Longo da Vida e os adultos pouco escolarizados}

A existência de uma oferta educativa não é suficiente para se assegurar o acesso dos potenciais interessados. Os estudos realizados revelam que o aumento da oferta formativa beneficia, sobretudo, o acesso daqueles que têm níveis de escolaridade mais elevados, isto porque "os indivíduos mais desfavorecidos e menos escolarizados são também aqueles que menos procuram e beneficiam das oportunidades de aprendizagem" (MELO; LIMA; ALMEIDA, 2002, p. 35).

O "mercado de aprendizagem" (FINGER; ASÚN, 2003), ou na perspectiva de Jarvis (2000) o "quase mercado" de aprendizagem, assenta numa relação entre a oferta e a procura, o que penaliza os adultos analfabetos e pouco escolarizados. Esses adultos dificilmente adoptam uma estratégia de procura de formação profissional na óptica que esta os possa colocar numa situação de vantagem competitiva face a outros adultos, pois "[...] o que menos sabe [do saber académico], quanto menos sabe, menos consciente é da sua necessidade de aprender, menos manifesta querer saber e menos ofertas tem 
para aprender" (SANZ FERNÁNDEZ, 2005, p. 90). Esse tipo de formação baseia-se, sobretudo, na forma escolar, o que é penalizante para os adultos não escolarizados ou pouco escolarizados, primeiro, porque estes nem sempre dominam as competências de leitura e escrita necessárias; segundo, pois percebem que os seus saberes experienciais não são valorizados, e, por último, porque estes adultos dificilmente conseguem atribuir sentido à situação, devido à organização e funcionamento das práticas.

A formação profissional desenvolvida numa lógica de qualificação de recursos humanos incide no ajustamento e adaptação funcional às exigências do mercado de trabalho. Desse modo, considera-se desajustada a necessidade de se apostar numa educação problematizadora, crítica e emancipatória - elementos fundamentais na alfabetização e educação de base de adultos. Quando se fala da promoção do "mercado da aprendizagem" repete-se o mesmo ciclo do passado, essas práticas de educação e formação não são destinadas nem acessíveis a todos os cidadãos.

Em Portugal, na última década, as orientaçôes que alicerçaram as políticas públicas de educação de adultos foram indiferentes "à maioria de uma população adulta que se encontra culturalmente e economicamente excluída do já ideologicamente celebrado 'mercado da aprendizagem'” (LIMA, 2005, p. 43). Essa forma de perspectivar a educação e a formação tem suscitado críticas, por se considerar que contribui para aumentar as desigualdades educativas, sociais e económicas entre a população. Num país como Portugal, em que os níveis de escolaridade são muito baixos, nomeadamente, entre a população de idade mais avançada, as consequências desses tipos de orientaçóes políticas ainda podem ser mais contraproducentes. De acordo com os Censos 2011 (INSTITUTO NACIONAL DE ESTATÍSTICA, 2011), 5\% da população adulta é analfabeta, $8,5 \%$ não tem qualquer nível de escolaridade completo, $30 \%$ dos adultos tem quatro anos de escolaridade ( $1^{\circ}$ ciclo) e 10\% têm seis anos de escolaridade ( $2^{\circ}$ ciclo). Estes valores assumem mais relevo quando se tem como referência a escolaridade mínima obrigatória neste momento - o $12^{\circ}$ ano de escolaridade. $\mathrm{Na}$ análise cruzada entre o nível de escolaridade e a idade, os valores ainda são mais expressivos. Em Portugal, $80 \%$ da população residente com mais de 65 anos é analfabeta. Entre os adultos que não possuem qualquer nível de escolaridade, $70 \%$ tem idade superior a 65 anos. Os valores revelam a importância das políticas públicas de alfabetização e de educação de base de adultos e, em simultâneo, uma intervenção consistente orientada 
para os adultos com idade superior a 65 anos, o que não se registou na última década. Trata-se de um problema que tem sido silenciado.

A análise que se apresenta de seguida resultou de uma investigação por nós realizada sobre o modo como as políticas internacionais, europeias e nacionais repercutem nas lógicas das práticas de educação e formação, num determinado território, e na participação dos adultos pouco escolarizados (CAVACO, 2009). Através da análise de elementos estatísticos referentes à execução da formação e das entrevistas aos responsáveis pela formação, quer de entidades empregadoras, quer de entidades formadoras, constatou-se que, no período e no território em estudo, as práticas de educação e formação de adultos foram predominantemente orientadas para as lógicas da ortopedia social e da qualificação individual. O que é notório na afirmação: "toda a formação tem o objectivo da empregabilidade ou objectivo social da formação" (Coordenadora de Formação). Em ambas as situaçóes, a formação de adultos é instrumentalizada ao serviço das políticas activas de emprego, por um lado, para tornar a economia mais competitiva, através da qualificação de recursos humanos; por outro lado, para minimizar os efeitos negativos do desemprego, tanto a nível individual como social.

A formação orientada numa lógica de ortopedia social, visa atenuar os efeitos negativos do desemprego, procurando manter ocupados os desempregados, para garantir uma certa paz social. Este tipo de formação é a mais expressiva no território em estudo. $\mathrm{Na}$ análise da formação realizada entre 2000 e 2004 , verifica-se que $59 \%$ dos formandos estavam desempregados. Os dados permitem afirmar que 19\% dos desempregados do território em estudo frequentaram formação, no período mencionado, enquanto que os formandos empregados representam apenas $4 \%$ do total de trabalhadores do território. Estes valores são elucidativos do investimento em formação de natureza paliativa, por parte das políticas públicas, para se minimiza o problema do desemprego no território em estudo.

As entidades que privilegiam uma intervençâo baseada na lógica de ortopedia social tendem a considerar a formação como a oferta de um serviço para os adultos desempregados, a Coordenadora de Formaçâo refere: "cada vez mais os nossos públicos são as franjas". A maioria dos adultos pouco escolarizados envolvidos em dinâmicas de formação no território em estudo frequentou práticas com finalidades paliativas, que visavam acautelar situaçóes de crise social e o cumprimento das metas quantitativas definidas na agenda política. A formação funcionou nesses casos como uma "almofada social", atenuando o 
problema do desemprego. Os adultos recebem uma bolsa que funciona, durante o período de frequência da formação, como a substituição do salário que não recebem - devido à sua condição de desempregados, além disso, estão ocupados, o que garante o controlo social do seu tempo livre. A existência da bolsa é um factor essencial para a adesão dos adultos, "os cursos sem bolsas não têm adesão, por muito que isto nos custe, não têm" (Coordenadora de Formação). Como refere um dos promotores entrevistados "durante o periodo da formação estão inseridos", o que permite minimizar o efeito do desemprego e, em simultâneo, não entrar na estatística do desemprego.

Os promotores reconhecem que essa formação não é procurada pelos adultos com o objectivo de aumentar os conhecimentos ou obter um certificado, mas pelo facto de ser concedida uma bolsa e de ser um espaço de socialização, como se verifica: "não é porque gostam muito daquela área ou porque gostam muito disto ou muito daquilo, há a questão do convivio, é a questão de terem contacto com outras pessoas [...], para não falar da questão da bolsa" (Coordenadora de Formação). Esta Coordenadora, sobre a bolsa destaca: "permite-lhe outro tipo de poder, a bolsa existe, eles estão desempregados, têm direito de a receber, se vêm para o curso por causa da bolsa é uma questão tão legítima como outra qualquer, encaramos a bolsa como o "chamariz", em alguns casos". A formação assume, nesse caso, um papel paliativo face ao problema do emprego, o que influencia a sua organização e funcionamento. Por exemplo, na selecção dos formandos as entidades promotoras não estão preocupadas em saber as experiências, os interesses e projectos dos adultos, mas apenas em assegurar que os adultos seleccionados cumprem os requisitos de admissão exigidos pelos programas e eixos de financiamento.

Os promotores desse tipo de formação percepcionam, com frequência, os adultos numa situação de défice, "défices de cognitividade e de vontade, ou seja, défices comportamentais e de projecto" (CORREIA; CARAMELO, 2003, p. 176), encarando-os como objecto de intervenção. Esse entendimento dos adultos é notório: "são pessoas problemáticas que nunca aproveitarão nada em lado nenhum [...] nós temos aqui formandos a quem já demos três, quatro hipóteses e não aproveitam, as pessoas não querem ajuda" (Coordenadora de Formação).

Os promotores não reconhecem o estatuto de sujeitos a estes adultos, não têm em conta as suas experiências, os seus saberes e as suas motivaçóes, o que é evidenciado na afirmação: "a parte profissional não é muito grave mesmo que não seja muito o gosto deles porque é só a primeira unidade, é só uma sensibilidade para aquela área" (Coordenadora da Formação). A formação baseia-se no modelo 
escolar, o que coloca problemas aos adultos pouco escolarizados, como se percebe na afirmação "se são pessoas com alguma escolaridade é público que aguenta as acçôes, se é um público de baixa escolaridade, se são beneficiários do rendimento social de inserção, já acaba por ser mais difícil, a integração, prendê-los à formação, leválos a que não faltem" (Coordenadora da Formação). Nesse caso, o que interessa salvaguardar é a assiduidade dos adultos, porque isso penaliza o financiamento da entidade promotora e pode colocar em risco a continuidade da formação. A formação é realizada em domínios que não exigem equipamentos específicos, em que a entidade promotora facilmente mobiliza formadores, e tem sobretudo uma dimensão teórica. Através das entrevistas percebeu-se que esta formação é baseada na forma escolar, privilegiando-se a exposição dos conteúdos, numa lógica de exterioridade, cumulatividade e repetição (CANÁRIO, 2005), o que é um obstáculo à participação dos adultos não escolarizados e pouco escolarizados.

A formação, predominantemente orientada segundo a lógica da ortopedia social, enquadra-se naquilo que Griffin (1999) designa de "modelo progressivo social-democrata". Essas práticas de formaçáo visam a adaptaçáo, o controlo social, a manutenção da ordem estabelecida, a prevençáo de conflitos sociais e resultam de políticas centralizadas do Estado-Nação. Trata-se de formaçóes que incidem na escolarização compensatória ou de segunda oportunidade, como é o caso do ensino recorrente, e em dinâmicas assistencialistas, caso da formação para desempregados e da formação para pessoas consideradas desfavorecidas. As finalidades, assim como a organização e o funcionamento das práticas de educação e formação orientadas na lógica de ortopedia social funcionam como obstáculos para a mobilização dos adultos pouco escolarizados. A sua aparente falta de motivaçáo pode funcionar, em muitos casos, como uma estratégia de "resistência" a práticas que os colocam em desvantagem perante os adultos mais escolarizados.

A formação orientada numa lógica de qualificação individual centra-se no desenvolvimento de competências e assenta na responsabilidade individual, com o intuito de promover o modelo de desenvolvimento económico contemporâneo. Nesse caso, a formação baseia-se na procura individual e num discurso que tem como enfoque a empregabilidade e a competitividade, e tem finalidades orientadas para a promoçáo do "turbo-capitalismo" (FINGER; ASÚN, 2003). A formaçấo organizada segundo esse tipo de lógica, enquadrase no designado "mercado" ou "quase mercado" de aprendizagem, como se verifica na afirmação: "vêm cá vender o produto deles e depois vão-se embora" (Coordenadora de Formação), por vezes são entidades que têm a sede fora do 
território, deslocam-se pontualmente para oferecer os seus serviços e aproveitar a procura existente. Nesse caso, apela-se à procura encantada de formaçâa (CANÁRIO, 2005), partindo do pressuposto que é condição necessária e suficiente para melhorar as condiçôes de trabalho - garantir a progressão e a mobilidade profissional, e para melhorar o acesso ao mercado de trabalho, ou seja, a inserção profissional. Os adultos que aderem a essa formação têm a expectativa que podem melhorar os seus conhecimentos e ficar em vantagem competitiva no mercado de trabalho face aos outros, "são pessoas que trabalham na área, querem aprofundar conhecimentos, aprender mais, melhorar" (Coordenadora de Formação).

Ao assentar na procura individual e dar primazia ao modelo escolar a formação organizada na lógica da qualificação individual se torna apelativa apenas para os adultos com um elevado nível de escolaridade e que interiorizaram o discurso presente na perspectiva da Aprendizagem ao Longo da Vida. Essas políticas e práticas beneficiam os adultos que encaram a educação como um dever, que interiorizaram o discurso da responsabilidade individual na gestão do problema do desemprego, e que concebem a educação e formação como estratégias ao serviço de um projecto pessoal e profissional, como modo de garantir a inserção, a mobilidade e a progressão profissional. Essa formação é frequentada por adultos com níveis de escolaridade elevados, como se percebe na afirmação: "há muito pessoal licenciado" (Coordenadora de Formação). A formação orientada para a lógica da qualificação individual é, essencialmente, frequentada pelos mais jovens e mais escolarizados, como se percebe na afirmação: "Normalmente são pessoas que têm a escolaridade obrigatória, normalmente têm o $9^{\circ}$ ano, são pessoas jovens [...], penso que raramente aparecem pessoas com mais de 40 anos" (Coordenadora de Formação). Os adultos pouco escolarizados dificilmente aderem a este tipo de dinâmicas, porque não se identificam e não reconhecem a importância das finalidades desta formação e percebem que a sua organização e funcionamento os coloca em desvantagem face aos mais escolarizados. Essas dinâmicas formativas normalmente não captam o interesse dos adultos pouco escolarizados, pois assentam no modelo escolar e dão primazia à componente teórica. Por outro lado, os cursos de formação, por norma, tem como requisito de acesso a escolaridade obrigatória, o que inviabiliza o acesso de alguns adultos pouco escolarizados, como se verifica: "Se a pessoa não tem a escolaridade obrigatória [requerida na sua idade] temos que a encaminhar para outro processo, se houver possibilidade de a integrar num curso EFA, óptimo, mas como os cursos 
EFA não estão a surgir a todo o momento" (Coordenadora de Formação), esta situação constitui um problema, por vezes, difícil de resolver.

A análise dos níveis de escolaridade dos formandos (CAVACO, 2009, p. 374) mostra que apenas $2,7 \%$ dos adultos pouco escolarizados do território em estudo participaram em formação profissional, entre 2000 e 2004 . No grupo dos adultos pouco escolarizados é notório que quanto elevado é o nível de escolaridade maior é a participação em formação. Apenas 0,6\% dos adultos com escolaridade inferior a quatro anos participaram em formação profissional, valor que é de 3,3\% para os adultos com quatro anos de escolaridade e 6,5\% para os adultos com seis anos de escolaridade. Os valores apresentados colocam em evidência a desvantagem dos adultos pouco escolarizados na participação em formação profissional, essa desvantagem é tanto maior quanto mais reduzido for o nível de escolaridade. Na análise por grupos etários (CAVACO, 2009, p. 375), confirma-se que os adultos de idade mais avançada são os que participam menos em formação. No território em estudo, $8 \%$ dos residentes com idade entre os 16 e os 19 anos participou em formação, esse valor é de 8,3\% no grupo dos 20-24 anos, e 6,8\% no grupo dos 25-34 anos. Esses valores são substancialmente mais baixos nos restantes grupos etários e atingem o mínimo entre os adultos com idade superior a 65 anos, sendo que apenas $0,3 \%$ participaram em formaçáo profissional e no grupo dos 55-64 anos, com uma taxa de participação de 0,7\%, a que seguem os grupos dos 35-44 anos com 1,9\% de participaçáo, o grupo dos 50-54 anos com 4\% de participação e o grupo dos 45-49 anos com 5\% de participação. Entre 2000 e 2004, a formação profissional no território em estudo foi, essencialmente, frequentada pelos adultos que possuem níveis de escolaridade mais elevados e pelos mais jovens.

A mobilização dos adultos pouco escolarizados para as dinâmicas de educação e formação formais e o sentido que lhes atribuem está muito dependente da relação que estabelecem com o saber. A relação com o saber resulta de "uma relaçáo com a linguagem, com o tempo, com a actividade no mundo e sobre o mundo, com os outros e consigo próprio" (CHARLOT, 2002, p. 94). As pessoas estabelecem relações distintas com o saber, umas preferem realizar aprendizagens por via dos saberes-objecto (académicos), outras preferem realizar aprendizagens através de actividades (acção). É "possível 'tornar-se alguém' através de diversas figuras do aprender, mas a sociedade moderna tende a impor a figura do saber-objecto (o sucesso escolar) como passagem obrigatória para se ter o direito de 'ser alguém”' (CHARLOT, 2002, p. 85). Essa situação, 
que reflecte a hegemonia da forma escolar e do saber académico, repercute-se nos modos de trabalho pedagógico, o que é notório no território estudado, conforme se referiu anteriormente.

Os adultos pouco escolarizados revelam motivação para a formação instituída quando atribuem sentido às dinâmicas e percebem que estão em condiçōes de ter sucesso. A atribuição de sentido às dinâmicas de educação e formação instituídas, por parte dos adultos pouco escolarizados, está muito associada às lógicas pelas quais estas se regem, o que se reflecte nas suas finalidades, na sua organização e funcionamento. Os adultos aderem a práticas de formação que vão de encontro aos seus interesses e que se afastam da forma escolar (CAVACO, 2009). Essas práticas são caracterizadas pela flexibilidade, pela reciprocidade de papéis entre os vários intervenientes, pela importância que atribuem ao processo e pela valorização da experiência e saberes dos participantes. As formaçóes baseadas na lógica da ortopedia social e na lógica da qualificação individual, para além de náo se revelarem apelativas, podem reforçar a ideia negativa da formação formal e contribuir para um maior afastamento dos adultos dessas dinâmicas, no futuro. A formação baseada nesses dois tipos de lógicas exige ao adultos o domínio de competências de literacia, o que funciona como um constrangimento para os adultos pouco escolarizados, e é com frequência um factor que origina receios, dúvidas e pode inviabilizar o acesso dos adultos, como se nota na afirmação: "Tinha algum receio, mas agora veio-me dizer que gosta muito e está muito satisfeita, a senhora tinha medo de já não aprender [...] se calhar já não tenho idade para estudar [...] Tenho medo de falhar, tenho medo" (Coordenadora de Formação). O medo de não conseguirem corresponder às suas expectativas e dos formadores gera ansiedade, situação que apenas é ultrapassada com o acompanhamento das equipas técnicas: "Nós tínhamos uma formanda, era talvez a mais velha, por volta de 50 anos, no principio quando se apercebeu que tinha informática ficou muito assustada, houve uma altura que chorava - Eu não vou conseguir, nunca mexi num computador" (Coordenadora da Formação).

A análise das práticas de formação no território estudado permite-nos afirmar que estas surgem fortemente influenciadas pelas orientaçôes resultantes das políticas europeias que se regem pela perspectiva da Aprendizagem ao Longo da Vida, condicionando o acesso de um largo número de adultos pouco escolarizados à formação, quer porque não são contemplados no público considerado "alvo", quer porque as políticas não prevêem a diversidade de práticas sociais inseridas no campo da formação de adultos. Todavia, o reduzido 
acesso dos adultos pouco escolarizados à formação parece ser percepcionado pelos actores locais como uma "desigualdade justa" (DUBET, 2000, p. 11), o que a torna facilmente tolerável. Esta desigualdade é atribuída, essencialmente, ao posicionamento e mérito diferenciado dos indivíduos, considerando que os seus insucessos e sucessos dependem das qualidades que conseguem evidenciar. Os mecanismos que individualizam as desigualdades contribuíram para "a perda de auto-estima e para o surgimento de problemas de consciência" (DUBET, 2000, p. 52), situação que se torna mais evidente no contexto actual de ênfase na responsabilidade, na individualização e na culpabilização.

A reduzida receptividade dos adultos pouco escolarizados à participação na formação resulta, em muitos casos, das suas inseguranças e receios face a formaçóes baseadas no modelo escolar, considerando que as suas dificuldades de leitura e escrita podem ser factores que geram insucesso, preferindo não arriscar para não experimentarem o fracasso, com todas as repercussóes que isso pode ter nas suas vidas.

Conforme diz Dubet (2000, p. 56), "os actores preservam a sua autoestima recusando participar num jogo no qual sabem à partida que vão perder". Esse argumento permite-nos compreender aquele que poderá ser o principal motivo para que os adultos pouco escolarizados não usufruam das oportunidades formativas disponíveis, constituindo-se como "não públicos" das modalidades educativas formais. A participação dos adultos pouco escolarizados na formação exige um conjunto de mudanças significativas nos espaços e tempos da formação, nos dispositivos e nos métodos. Torna-se fundamental reequacionar estes aspectos "sempre que se trate de atrair este vasto 'não público', e não apenas os já motivados e convictos dos benefícios de novos saberes e saber-fazer" (MELO, 2004, p. 13).

De acordo com os elementos identificados, constata-se a existência de um paradoxo: a perspectiva da Aprendizagem ao Longo da Vida e as políticas europeias que nela se baseiam, assim como as políticas públicas nacionais que daí resultam, têm vindo a apresentar-se como elementos de retrocesso, pois não prevêem todo tipo de educação nem o acesso de todos os adultos, independentemente da idade, escolaridade e situaçáo face à actividade profissional.

\section{Conclusão}

O discurso social e político tem vindo a basear-se no pressuposto que os adultos não escolarizados e pouco escolarizados não estariam em condiçôes 
de assegurar a sua inserção social e profissional e de contribuir para o desenvolvimento do país. Esse tipo de discurso, inspirado na Teoria do Capital Humano, estabelece uma relação linear e directa entre qualificação escolar, emprego e desenvolvimento, deu lugar a "uma abordagem economicista, e portanto redutora, deste fenómeno" (CANÁRIO, 1999, p. 54).

Nas últimas décadas, tornou-se evidente que essa relação linear e directa não existe, porquanto "o aumento generalizado das qualificaçóes escolares é concomitante com o crescimento do desemprego como fenómeno estrutural de massas" (CANÁRIO, 2006, p. 28), com a precariedade dos vínculos laborais e com o agravamento das desigualdades sociais. A perspectiva antes referida, para além de contribuir para a estigmatização social dos adultos não escolarizados e pouco escolarizados, teve consequências na "instrumentalização da educação de adultos" que passou a estar "estreitamente ligada à 'economizaçáo' da vida social" (FINGER; ASÚN, 2003, p. 116), enquanto instrumento privilegiado ao serviço do desenvolvimento económico e da competitividade.

Assumir a ligação entre a educação de adultos e o modelo de desenvolvimento económico implica admitir a sua importância no controlo social e na gestão das relações de poder. As políticas e práticas de alfabetização e de educação de base pautaram-se, em Portugal, com frequência, na opção entre duas estratégias: "Excluir da educação a maioria da população para melhor a controlar? Ou controlá-la melhor através de uma inclusão maciça na (e pela) educação?” (MELO, 2004, p. 11). Estas questóes são pertinentes para se analisar e debater, actualmente, as finalidades das políticas públicas de educação e formação de adultos no contexto Português.

Como se verificou anteriormente, a maior parte dos recursos financeiros disponibilizados para a formação são gastos em práticas orientadas numa lógica de ortopedia social, cuja principal finalidade é minimizar os efeitos negativos do desemprego, mantendo as pessoas ocupadas. Desse modo, a formação profissional tem uma função social oculta, um género de tampão ao desemprego, usando a metáfora de José Machado Pais (2001), quando considera que esse é o papel desempenhado pela escola junto de alguns jovens, no sentido que os mantém ocupados e sem intenção de entrada no mercado de trabalho, o qual não tem lugares suficientes para acolhê-los.

A perspectiva da Aprendizagem ao Longo da Vida, enquanto poderosa retórica contribuiu, inegavelmente, nas últimas quase duas décadas, para que a educação de adultos se transformasse em apenas uma entre muitas ofertas do 
"mercado cultural" da sociedade, tornando este campo muito susceptível "às pressôes da competição, às condições de oferta e procura e da comercialização" (FINGER; ASÚN, 2003, 111-112).

Sabendo-se que, actualmente, as politicas públicas de educação e formação não envolvem todos os adultos e não compreendem todo o tipo de educação, podemos colocar um conjunto de questôes: As políticas e práticas de educação e formação de adultos estão ao serviço de quem? E para quê? Estão inseridas em políticas cuja principal finalidade não se cumpre - a competitividade económica. Os adultos envolvidos nas dinâmicas de educação e formação mais expressivas no território não reconhecem a formação como um processo de aprendizagem que lhes permita a inserção ou mobilidade profissional. Os promotores assumem que a formaçáo realizada visa, na maior parte dos casos, a minimização dos problemas sociais gerados pelo desemprego. Os empresários contactados no âmbito da investigação realizada não reconhecem pertinência nem adequação às medidas políticas no domínio da educação e formação de adultos, nem à forma como se materializam na prática.

As políticas de educação e formação de adultos, nas últimas décadas, contaram com montantes financeiros muito avultados, sendo orientadas segundo a lógica do mercado ou do quase mercado. Nesse sentido, contribuíram para a constituição de um novo mercado - o mercado da formação, o qual está organizado segundo uma lógica de oferta e de procura. Este mercado assenta numa rede de promotores públicos e privados, com um vasto número de técnicos que ocupam as mais variadas funçóes. Apenas a título ilustrativo, refere-se o caso das equipas dos Centros Novas Oportunidades as quais empregam cerca de 125 mil pessoas, a maior parte com formação graduada. É caso para afirmar que em Portugal, o mercado da formação tem contribuído de uma forma inegável para aumentar as oportunidades de inserção e de (re)inserção profissional entre os jovens e os adultos licenciados.

A formação profissional é entendida como paliativa, envolve interesses poderosos e representa um importante mecanismo de gestão da concertação social e do desemprego (CANÁRIO 2005). Parte-se do princípio que a formação contribui para atenuar "a crise e a anomia social" (LIMA, 2005, p. 50). A formação é percepcionada como paliativa, porque permite ocupar e atribuir uma bolsa aos adultos durante um determinado tempo, o que contribui para minimizar os efeitos negativos do desemprego. Todavia, parece-nos que o impacto mais importante das políticas públicas de educação e formação 
é precisamente o facto de contribuírem para o surgimento do mercado da formação, o qual garante a inserção profissional a milhares de adultos com formação de nível superior. A formação é entendida, neste caso, como uma espécie de "almofada social" que amortece as consequências sociais e económicas do problema do desemprego e como forma de assegurar o emprego, ainda que temporário e precário, a jovens com níveis de escolaridade muito longos. $\mathrm{O}$ mercado da formaçáo serve, neste caso, dois propósitos, ainda que não sejam reconhecidos explicitamente nos documentos oficiais: ocupar e, assim, manter afastados do mercado de trabalho os adultos desempregados e minimizar o problema do desemprego dos adultos com formaçáo de nível superior. Desse modo, o mercado da formação é uma estratégia que permite, na sua essência, "manter o turbo-capitalismo em funcionamento" (FINGER, 2005, p. 29).

A excessiva instrumentalização da formação em função dos problemas decorrentes do modelo de desenvolvimento contemporâneo e a sua inclusão nas políticas activas de emprego provocam um conjunto de constrangimentos na organização e funcionamento das práticas de formação. No território estudado a dinâmica da formação é, essencialmente, estruturada em função do cumprimento de metas políticas e dos financiamentos comunitários. A formação é percepcionada numa dimensão mais administrativa do que educativa. É caso para dizer que "a azáfama, o intervencionismo incontrolado e a multiplicação de respostas contrastam com o défice dos dispositivos que permitem colocar perguntas" (CORREIA; CARAMELO, 2003) e que se adaptam às especificidades dos públicos e dos contextos. A necessidade de concretizar as orientaçóes políticas, europeias e nacionais, conduz as entidades formadoras a organizarem a sua intervenção em função de metas quantitativas, situação que suscita uma azáfama intervencionista, dificilmente compatível com a organização de formação "à medida" dos problemas e dos recursos das pessoas e comunidades.

As políticas e práticas enquadradas na perspectiva da Aprendizagem ao Longo da Vida baseiam-se na escolarizaçáo e visam o controlo social das pessoas, sobretudo daquelas desempregadas, provocando a sua dependência face ao sistema instituído. Essas políticas e práticas de educação e formação de adultos são, essencialmente, baseadas no modelo escolar e orientadas para adaptação e controlo social, contrariando, desse modo, os princípios da educação de adultos defendidos por Ivan Illich (1971), os quais na nossa perspectiva são basilares para se garantir uma educação para todos e a valorização 
de todo o tipo de educação. Contrariamente, ao que se tem vindo a registar nas políticas públicas e nas práticas de educação e formação de adultos daí resultantes, trata-se de valorizar a aprendizagem por oposição à escolarização; a convivialidade por oposição à manipulação; a responsabilização por oposiçâo à desresponsabilização; e a participação por oposição ao controlo. É nesse sentido que se advoga que as políticas e práticas de educação e formação de adultos, em geral, e as direccionadas para os adultos pouco escolarizados, em particular, ganham se forem estruturadas "como respostas a questóes emergentes de projectos - individuais ou colectivos -que os adultos vivam intensamente" (MELO, 2004, p. 14). Ou seja, parte-se do princípio "que o papel central da educação e formação consiste, então, em ajudar a problematizar” (CANÁRIO, 2001b, p. 96) e a construir o futuro, o que implica uma aprendizagem orientada para a leitura crítica do mundo e para a sua transformação. Apenas nestas condiçóes é possível "passar da escolarização para a educação" (CANÁRIO, 2001b, p. 96). A oferta de educação e formação por si só não gera a procura, o que é notório com a reduzida participação dos adultos náo escolarizados e pouco escolarizados na formaçấo existente no território. A maioria desses adultos constitui os designados "não públicos" da educação e formação de carácter formal. Para contornar essa situação e atrair esse vasto "não público" é fundamental a "reinvenção" de novas políticas e dinâmicas educativas e formativas, no que se refere aos "espaços, tempos e ritmos, contextos, percursos, procedimentos, assuntos, métodos, agentes e agências" (MELO, 2004, p. 13).

\section{REFERÊNCIAS}

BOURDIEU, Pierre. Contrafogos. Oeiras: Celta, 1998.

CANÁRIO, Rui. Educação de Adultos: um campo e uma problemática. Lisboa: Educa, 1999.

CANÁRIO, Rui. A "aprendizagem ao longo da vida”: análise crítica de um conceito e de uma política. In: CANÁRIO, Rui (Org.). Formação e situaçôes de trabalho. 2 ed. Porto: Porto Editora, 2001a. p.191-207.

CANÁRIO, Rui. Adultos: da escolarização à educação. Revista Portuguesa de Pedagogia, Coimbra, v. 35, n. 1, p. 85-99, 2001b.

CANÁRIO, Rui. O que é a Escola? Um Olhar Sociológico. Porto: Porto Editora, 2005. 
CANÁRIO, Rui. Multiplicar as oportunidades formativas. Formar, Lisboa, $v$. 54, p. 28-34, 2006.

CARRÉ, Philippe; CASPAR, Pierre. Bases et usages du Traité. In: CARRÉ, Philippe; CASPAR, Pierre (Org.). Traité des sciences et des techniques de la formation. Paris: Dunod, 1999. p. 1-12.

CASPAR, Pierre. Editorial. Education Permanente, Paris, v. 129, n. 4, p. 5-11, 1996.

CAVACO, Carmen. Aprender Fora da Escola: percursos de formação experiencial. Lisboa: Educa, 2002.

CAVACO, Carmen. Adultos Pouco Escolarizados: diversidade e interdependência de lógicas de formação. 2009. 632f. Tese (Doutorado em Ciências da Educação/Formação de Adultos) - Universidade de Lisboa. Faculdade de Psicologia e de Ciências da Educação, 2009. Disponível em: <http://repositorio.ul.pt/handle/10451/972>. Acesso em: 2 jan. 2012.

CHARLOT, Bernard. Du rapport au savoir: éléments pour une théorie. 3. ed. Paris: Anthropos, 2002.

CCE. Livre blanc sur l'éducation et la formation: enseigner et apprendre -Vers la société cognitive. Luxemburgo: Comissão Europeia, 1995.

CCE. Comissão das Comunidades Europeias. Memorando sobre a aprendizagem ao longo da vida. Bruxelas, 30 out. 2000. Disponível em:<http://ec.europa.eu/education/lifelong-learning-policy/doc/policy/ memo_pt.pdf $>$. Acesso em: 4 jan. 2012.

CORREIA, Alberto; CARAMELO, Joáo. Da mediação local ao local da mediação: figuras e políticas. Educação, Sociedade \& Culturas, Porto, v. 20, p. 167-191, 2003.

DALE, Roger. Globalização e educação: demonstrando a existência de uma "cultura educacional mundial comum" ou localizando uma "agenda globalmente estruturada para a educação"? Educação e Sociedade, v. 25, n. 87, p. 423-460, maio/ago. 2004. Disponível em: <http://www.scielo.br/pdf/es/ v25n87/21464.pdf>. Acesso em: 18 mar. 2008.

DOMINICÉ, Pierre. Expérience et apprentissage: faire de nécessité vertu. Education Permanente, Paris, n. 100/101, p. 57-65, 1989. 
DUBAR, Claude. La formation accroît-elle aujourd'hui les inégalités. Education Permanente, Paris, v. 129, n. 4, p. 19-28, 1996.

DUBET, François. Les inégalités multipliées. La Tour d'Aigues: Éditions de l'Aube, 2000.

FINGER, Matthias. A educação de adultos e o futuro da sociedade. In: CANÁRIO, Rui; CABRITO, Belmiro (Org.). Educação e Formação de Adultos: mutaçóes e convergências. Lisboa: Educa, 2005. p.15-30.

FINGER, Matthias; ASÚN, José Manuel. A Educação de Adultos numa encruzilhada: aprender a nossa saída. Porto: Porto Editora, 2003.

FREIRE, Paulo. Pedagogia do Oprimido. Porto: Afrontamento, 1972.

GIDDENS, Anthony. As consequências da modernidade. 4 ed. Oeiras: Celta, 2000.

GONTCHAROFF, Georges. A la recherche des territoires. Globonet, Paris, 2 avr. 1999. Disponível em: <http://www.globenet.org/archives/web/2006/ www.globenet.org/horizon-local/humanisme/1gontcharoff.html>.

GRIFFIN, Colin. Lifelong learning and welfare reform. Journal of Lifelong Education, v. 18, n. 6, p. 431-452, 1999.

ILLICH, Ivan. Une société sans école. Paris: Éditions du Seuil, 1971.

INSTITUTO NACIONAL DE ESTATÍSTICA. Recenseamento Geral da População. Lisboa: INE, 2001.

JARVIS, Peter. Globalização e o mercado de aprendizagem. In: LIMA, Licínio (Org.). Educação de Adultos. Braga: Universidade do Minho, 2000. p. 29-41.

JOSSO, Marie-Christine. Experiências de vida e formação. Lisboa: Educa, 2002.

LAOT, Francoise; ORLY, Paul. Éducation et formation des adultes: histoire et recherches. Saint-Fons: Institut National de Recherche Pédagogique, 2004.

LE GOFF, Jean-Pierre. L'érosion des idéaux de l'éducation permanente.

Education Permanente, v. 129, p. 29-33, 1996.

LIÉTARD, Bernard. Se reconnaître dans le maquis des acquis. Education Permanente, Paris, v. 133, p. 65-74, 1997. 
LIMA, Licínio. Organização e administração de projectos de investigação e desenvolvimento em educaçáo de adultos. In: LIMA, Licínio (Org.). Fórum I: Educação de Adultos. Braga: Universidade de Braga, 1994. p. 27-46.

LIMA, Licínio. A educação de adultos em Portugal (1974-2004): entre as lógicas da educação popular e da gestáo de recursos humanos. In: CANÁRIO, Rui; BELMIRO, Cabrito (Org.). Educação e formação de adultos: mutaçôes e convergências. Lisboa: Educa, 2005. p. 31-60.

MELO, Alberto. O acesso dos públicos mais desfavorecidos à educação e formação. Formar, Lisboa, v. 46, n. 50, p. 10-15, 2004.

MELO, Alberto; LIMA, Licínio; ALMEIDA, Mariana. Novas politicas de educação e formação de adultos: o contexto internacional e a situação Portuguesa. Lisboa: Agência Nacional de Educação de Adultos, 2002.

NÓVOA, António; RODRIGUES, Cristina. "Prefácio". In: CANÁRIO, Rui; CABRITO, Belmiro (Org.). Educação e Formação de Adultos: mutaçôes e convergências. Lisboa: Educa, 2005. p. 7-14.

PAIS, José Machado. Ganchos, Tachos e Biscates: jovens, trabalho e futuro. Porto: Âmbar, 2001.

PINEAU, Gaston (Org.). Éducation ou aliénation permanente? Repères mythiques et politiques. Paris: Dunod, 1977.

ROSE, Nikolas. Powers of freedom: reframing political thought. Cambridge: Cambridge University Press, 1999.

SANZ FERNÁNDEZ, Florentino. Modelos actuais de educação de pessoas adultas. In: CANÁRIO, Rui; CABRITO, Belmiro (Org.). Educação e

Formação de Adultos: mutaçóes e convergências. Lisboa: Educa, 2005. p.7396.

UNESCO. Rapport Final: Quinta Conferência Internacional de Educação de Adultos (Hamburgo). Paris, 1997a.

UNESCO. Agenda por l'Avenir: Quinta Conferência Internacional de Educação de Adultos (Hamburgo). Paris, 1997b. 


\section{Formation des adultes Adult education with peu scolarisés:paradoxes low level of schooling: de la perspective de contradictions of policy l'Apprentissage Tout au Long Lifelong Learning de la Vie}

\section{Résumé}

L'article a pour objectif faire une analyse critique de la perspective politique de l'Apprentissage Tout au Long de la Vie, par rapport aux politiques et pratiques des adultes peu scolarisés au Portugal. On considère que, au contraire du discours politique envisagé dans les documents de la Commission Européenne et des orientations politiques nationales, la perspective d'Apprentissage Toute au Long de la Vie ne concerne pas toutes les modalités éducatives ni toutes les personnes. Lanalyse en question est le resultat d'une recherche qualitative basée sur le recueil des documents et des statistiques. Ces donnés furent complementés par un étude de cas dont on a fait des entretiens semi-structurés avec les responsables de la formation des institutions publiques et privées de cinq mairies du sud du Portugal. Les données empiriques recueillies mettent en évidence que les orientations concernant à la perspective de l'Apprentissage Tout au Long de la Vie donnent lieu à des pratiques de formation très limitées, qui ne permettent pas le développement de la richesse et de la diversité des pratiques d'éducation et ansi, limiten la participation de toutes les adultes. Dans ce territoire, les pratiques de formation

\begin{abstract}
The aim of this article is to make a critical analysis of the political perspective of Lifelong Learning, taking into account the policies and practices for adults with a low level of schooling in Portugal. We consider that the policy speech of the European Commission about Lifelong Learning is inconsistent because the educational practices based in this narrative do not promote the education for all nor does it include all educational practices. This qualitative research is based in the documental and statistics data. These data were supplemented with information gathered in a case study, which centered itself on five councils in the south of Portugal. In the case study, the empirical data resulted from semi-structured interviews with those responsible for training in public and private institutions and statistical data. The empirical data collected reflects that the policy guidelines concerning the Lifelong Learning give rise to circumscribed formation practices which do not meet the wealth and diversity of the educational process and diversity of the educational process and, for this reason, do not involve the citzens as a whole. Most of the training performed
\end{abstract}


qui adviennent des politiques publiques sont inspirées dans la forme scolaire, ce qui difficulte la participation des adultes peu scolarisés.

Mots-clés: Education des Adultes. Politiques d'Éducation des Adultes. Adultes Non Scolarisés.

\section{Carmem Cavaco}

E-mail: carmen@ie.ul.pt in the study area is based on a scholar form, which penalizes the participation of adults with low level of schooling. Keywords: Adult Education. Out- of-school population. Adult Education Policy. Out-of-school adults.

Recebido em: 29/3/2013

Ultima versáo recebida em: 18/5/2013

Aprovado em:20/5/2013 